\title{
Re: Early postoperative outcome of bipolar transurethral enucleation and resection of the prostate
}

Hong Kong Med J 2016;22:188-9

DOI: $10.12809 / \mathrm{hkmj} 164831$

To the Editor-I enjoyed the article by Cho et $\mathrm{al}^{1}$ titled, "Early postoperative outcome of bipolar transurethral enucleation and resection of the prostate," published in the December 2015 issue of Hong Kong Medical Journal. I noted with interest that the authors reported no urethral stricture, meatal stenosis, or bladder neck contracture at 3 months despite the larger prostates and more difficult procedures (mean preoperative transrectal ultrasonography prostate volume of $71.9 \mathrm{~cm}^{3}$ and mean operating time of 86.1 minutes). Komura et $\mathrm{al}^{2}$ recently published the results of their randomised trial of monopolar (abbreviated M-TURP) versus bipolar transurethral resection of the prostate (abbreviated TURis) in the April 2015 issue of the $B J U$ International. They reported "a significant difference in postoperative urethral stricture rates between groups was detected $(6.6 \%$ in M-TURP vs $19.0 \%$ in TURis; $\mathrm{P}=0.022$ ). After stratifying patients according to prostate volume, there was no significant difference between the two treatment groups with regard to urethral stricture rates in patients with a prostate volume of $\leq 70 \mathrm{~mL}(3.8 \%$ in M-TURP vs $3.8 \%$ in TURis), but in the TURis group there was a significantly higher urethral stricture rate compared with the M-TURP group in patients with a prostate volume $>70 \mathrm{~mL}(20 \%$ in TURis vs $2.2 \%$ in M-TURP; $\mathrm{P}=0.012)$." The difference was also noted by Tang et $\mathrm{al}^{3}$ who suggested "the risk factors for B-TURP (to result in more urethral strictures) included a larger resectoscope diameter, higher ablative energy, and longer procedure time" in their review and meta-analysis published in the September 2014 issue of the Journal of Endourology. My personal experience is more in line with the previously reported experiences in that I appear to have less bleeding with the bipolar technique and less worry about transurethral resection syndrome. Hence I resect more, operate for longer, and end up with at least 3 times more strictures after switching from the monopolar to the bipolar technique, despite routinely performing preoperative urethral dilatation. I am interested to find out how the incidence of urethral strictures will now compare with results of monopolar TURP in Cho et al's ongoing series after they have operated on more patients, and whether the authors perform routine preoperative urethrotomy or other prophylaxis against urethral stricture.
Benson Yeung *, FHKAM (Surgery)

Private surgeon, Hong Kong

* Corresponding author: dr.bensonyeung@gmail.com

\section{References}

1. Cho CL, Leung CL, Chan WK, Chu RW, Law IC. Early postoperative outcome of bipolar transurethral enucleation and resection of the prostate. Hong Kong Med J 2015;21:528-35.

2. Komura $\mathrm{K}$, Inamoto $\mathrm{T}$, Takai $\mathrm{T}$, et al. Incidence of urethral stricture after bipolar transurethral resection of the prostate using TURis: results from a randomised trial. BJU Int 2015;115:644-52.

3. Tang Y, Li J, Pu C, et al. Bipolar transurethral resection versus monopolar transurethral resection for benign prostatic hypertrophy: a systematic review and metaanalysis. J Endourol 2014;28:1107-14.

\section{Authors' reply}

We appreciate Dr Yeung's comments and specifically respond to his concerns as follows.

Urethral stricture and bladder neck contracture after transurethral surgery usually occurs after 6 months postoperatively. ${ }^{1}$ Longer follow-up is required to conclude the incidence of urethral stricture and bladder neck contracture in our patients. The time interval for occurrence of meatal stenosis after transurethral surgery is less clearly defined in the literature. In our experience, meatal stenosis is uncommon in the first 6 months following surgery. Our study reported the early postoperative outcome of bipolar transurethral enucleation and resection of the prostate (TUERP). The incidence of urethral stricture and bladder neck stenosis 3 months postoperatively is expected to be low. We will continue to follow up our patients and plan to report intermediate and long-term results in the future.

The concern about a higher incidence of urethral stricture after bipolar transurethral resection of the prostate (TURP) was raised by the recent articles by Komura et al and Tang et al. ${ }^{1,2}$ Their technique differed to ours, however. The concern about a higher incidence of postoperative urethral stricture remains. There are a lack of clinical data that address the long-term results of bipolar TURP including the incidence of urethral stricture. ${ }^{3}$ Size of sheath, duration of operation, and current leak 
have all been suggested as possible mechanisms that cause urethral stricture following bipolar TURP. We perform bipolar TUERP using a 26-Fr resectoscope which is the same as bipolar TURP. By utilising the bipolar TUERP technique, less electrocautery is used compared with bipolar TURP. The enucleation procedure is performed mechanically with the sheath. Electrocautery is used to cauterise the denuded vessels only. The relatively avascular subtotally enucleated adenoma facilitates an easier resection process with less need for electrocautery. In theory, the incidence of urethral stricture after bipolar TUERP should be lower than that for bipolar TURP if current leak is the major mechanism that underlies development of urethral stricture. Comparative studies with long-term follow-up are required to reach a conclusion.

We do not routinely perform preoperative urethral dilatation. A 26-Fr resectoscope can be inserted without difficulty in most of our patients. Unfortunately, there is no evidence to suggest that preoperative measures, including urethrotomy, can effectively reduce the incidence of postoperative urethral stricture.

CL Cho *, FRCSEd (Urol), FHKAM (Surgery)

Clarence LH Leung, MRCSEd

Wayne KW Chan, FRCSEd (Urol)

Ringo WH Chu, FRCSEd (Urol), FHKAM (Surgery)

IC Law, FRCSEd (Urol), FHKAM (Surgery)

Division of Urology, Department of Surgery, Kwong Wah Hospital,

Yaumatei, Hong Kong

* Corresponding author: chochaklam@yahoo.com.hk

\section{References}

1. Komura K, Inamoto T, Takai T, et al. Incidence of urethral stricture after bipolar transurethral resection of the prostate using TURis: results from a randomised trial. BJU Int 2015;115:644-52.

2. Tang Y, Li J, Pu C, et al. Bipolar transurethral resection versus monopolar transurethral resection for benign prostatic hypertrophy: a systematic review and metaanalysis. J Endourol 2014;28:1107-14.

3. Mamoulakis C, Ubbink DT, de la Rosette JJ. Bipolar versus monopolar transurethral resection of the prostate: a systematic review and meta-analysis of randomized controlled trials. Eur Urol 2009;56:798-809. 